\title{
Pagetoid reticulosis with CD30 positivity and cytotoxic/suppressor cells
}

- $\quad$ Witold K. Jacyk

- Wayne Grayson ${ }^{2}$,

- Jurgen Erich Dinkel ${ }^{3}$ and

- $\quad$ Luis Requena ${ }^{4}$

${ }^{1}$ Department of Dermatology, University of Pretoria, Pretoria, South Africa

${ }^{2}$ Department of Anatomical Pathology, University of Witwatersland, Johannesburg, South Africa

${ }^{3}$ Department of Anatomical Pathology, University of Pretoria, Pretoria, South Africa, and

${ }^{4}$ Department of Dermatology, Fundación Jiménez Díaz, Universidad Autónoma, Madrid, Spain

[Figures and tables at the bottom of the document]

\section{Abstract}

Pagetoid reticulosis (PR) is a low-grade primary cutaneous T-cell lymphoma that usually presents as a solitary, slowly enlarging erythematous or hyperkeratotic plaque on the distal areas of the extremities. Histopathologically, it is characterized by a dense, bandlike infiltrate of atypical lymphocytes with prominent epidermotropism within a hyperplastic epidermis, and immunophenotypic studies show in most cases, a CD4positive T-helper phenotype for the neoplastic lymphocytes. We describe an African man with a more than 20-year history of an acral lesion of PR, which was histopathologically characterized by lymphocyte immunophenotype consisting of CD8- and CD30-positive cells. We discuss the differential diagnosis with other primary cutaneous lymphoproliferative disorders showing similar immunophenotype. This case shows that CD30-positive PR should be included as a rare variant within the spectrum of CD30- 
positive primary cutaneous lymphoproliferative disorders. As in other primary cutaneous CD30-positive lymphoproliferative processes, lesions of CD30-positive PR show an indolent course and a benign biological behavior.

Pagetoid reticulosis (PR), also named Woringer-Kolopp disease, is a low-grade primary cutaneous T-cell lymphoma that usually presents as a solitary, slowly enlarging erythematous or hyperkeratotic plaque on the distal areas of the extremities. Histopathologically, it shows a prominent infiltrate of atypical lymphocytes within a hyperplastic epidermis. Immunophenotypic studies in lesions of PR have led to the recognition of different phenotypes for the large atypical epidermotropic lymphocytes. The CD4-positive T-helper phenotype appears the most common. ${ }^{1 \cdot 3}$ We describe an African man with a more than 20-year history of an acral lesion of PR, which was histopathologically characterized by lymphocyte immunophenotype consisting of CD8and CD30-positive cells.

\section{Case Report}

The patient was a 43-year-old African man who presented with a more than 20-year history of a large lesion on the right foot. A well-defined, markedly hypopigmented, hyperkeratotic plaque involving the dorsum and the volar aspect of the foot (Fig. 1A,B) was seen. The regional lymph nodes were not palpable. Physical examination was otherwise normal. He was HIV negative, with CD4 count of $983 \times 10^{6} / 1$. Laboratory investigations included full blood count, with platelet count, erythrocyte sedimentation rate and serum protein, glucose, electrolyte, urea, creatinine and liver enzyme levels, all of which were within normal limits. Serology for syphilis, including rapid plasma reagin (RPR) and treponena pallidum hemagglutination assay (TPHA), resulted negative. Virological studies (enzyme-linked immunosorbent assay) for cytomegalovirus and Epstein-Barr virus did not show immunoglobulin (Ig)M antibodies, while IgG titers were low.

An incisional biopsy showed a markedly hyperplastic epidermis, with acanthosis, hyperkeratosis and focal parakeratosis. The underlying superficial dermis exhibited a dense, band-like lymphoid infiltrate. The infiltrate consisted predominantly of mature 
lymphocytes, which were admixed with scattered markedly atypical lymphocytes and plasma cells. The most striking feature consisted of the presence of a markedly epidermotropic infiltrate of atypical lymphocytes, morphologically identical to those singly distributed within the papillary dermal infiltrate. The atypical cells in the epidermis were aggregated into microabscess-like structures, predominantly in the lower epidermis, with preservation of basal epidermal keratinocytes for the most part. The intraepidermal aggregates varied greatly in size, with some consisting only of two to three cells, while others contained larger number of atypical lymphocytes. Singly distributed atypical epidermotropic lymphoid cells were also present. The atypical epidermotropic lymphoid infiltrate extended to the level of the stratum granulosum (Fig. 2A,B). Immunohistochemical studies confirmed the T-cell immunophenotype of the atypical lymphocytes because they were $\mathrm{CD} 3+$ and $\mathrm{CD} 20-$. The scattered mature $\mathrm{T}$ lymphocytes in the upper dermis stained positively with CD4, whereas the large lymphoid cells did not stain with this marker. In contrast, the CD8 immunostaining was detected in the overwhelming majority of the intra-epidermal neoplastic cells (Fig. 3A,B). Almost all atypical lymphoid cells also expressed immunoreactivity for CD30 (Fig. 4A,B).

\section{Discussion}

The clinical diagnostic alternatives in our case were chromomycosis, acral mycosis fungoides (mycosis fungoides palmaris et plantaris, MFPP) and PR. The clinical picture, the indolent long-term course of the lesions as well as the marked epidermotropism seen in the histopathological study, was in favor of PR.

There are some immunophenotypic differences between MFPP and PR. In MFPP, the neoplastic lymphocytes are invariably CD4-positive T-helper cells. In contrast, although the neoplastic cells in PR are most often CD4+, ${ }^{1-3}$ they may be $\mathrm{CD} 8+/ \mathrm{CD} 4-^{1,4=6}$ or double $\mathrm{CD} 4 / \mathrm{CD} 8-{ }^{1,5-7}$

The most striking histopathological feature of our case was the strong positive staining of almost all atypical cells with CD30. In mycosis fungoides, CD30 immuno-expression may be seen in transformation lesions, but this immunoreactivity is mostly confined to the dermal neoplastic lymphocytes cells rather than to the intra-epidermal ones. 
CD30 immunoreactivity has been previously reported in PR, but only a few cases showed a predominance of these cells. ${ }^{5,6,8}$ Table 1 lists the reported cases of PR with marked CD30 immunoreactivity. There is a great similarity between our case and the patient reported by Smoller et al. ${ }^{6}$ in terms of the size of the lesion, its long duration, the apparent benignancy of the process and the immunophenotypic features (CD8 positivity, CD4 negativity and the overwhelming predominance of cells showing CD30 positivity). The clinical appearance and the benign course prompted consideration of another CD30 (Ki-1)-positive lymphoproliferative disorder, namely primary cutaneous CD30-positive anaplastic large cell lymphoma. ${ }^{9}$ Although CD30-positive primary cutaneous lymphoma also pursues an indolent course and may even exhibit a tendency to spontaneous regression, it is characterized by rapid initial growth, $\mathrm{CD} 4$ immunoreactivity rather CD8 positivity and lack of epidermotropism.

Primary cutaneous CD8-positive epidermotropic T-cell lymphomas share the CD8 positivity and the epidermotropism with our case but usually run an aggressive clinical course and have widespread cutaneous involvement. Furthermore, CD30 immunoexpression was observed in only 2 of 17 patients with this type of lymphoma in the series of Berti et al. ${ }^{10}$ Our patient had a solitary lesion with slow growth and indolent biological behavior for more than 20 years, all clinical features characteristic of PR.

In conclusion, CD30-positive PR should be included as a rare variant within the spectrum of CD30-positive primary cutaneous lymphoproliferative disorders. As in other primary cutaneous CD30-positive lymphoproliferative processes, lesions of CD30-positive PR show an indolent course and a benign biological behavior. 


\section{References}

1.

Deneau DG, Wood GS, Beckstead J, Hoppe RT, Price N. Woringer-Kolopp disease (pagetoid reticulosis). Four cases with histopathologic, ultrastructural, and immunohistologic observations. Arch Dermatol 1984; 120: 1045.

2.

Slater D, Goepel J, Walker A, Corbett P. Lymphocyte subsets in pagetoid reticulosis. $\mathrm{Br}$ J Dermatol 1984; 111: 244.

3.

Burns MK, Chan LS, Cooper KD. Woringer-Kolopp disease (localized pagetoid reticulosis) or unilesional mycosis fungoides? An analysis of eight cases with benign disease. Arch Dermatol 1955; 131: 325.

4.

MacKie RM, Turbitt ML. A case of pagetoid reticulosis bearing the T cytotoxic suppressor surface marker on the lymphoid infiltrate: further evidence that pagetoid reticulosis is not a variant of mycosis fungoides. $\mathrm{Br} J$ Dermatol 1984; 110: 89. 5.

Mielke V, Wolff HH, Winzer M, Sterry W. Localized and disseminated pagetoid reticulosis. Diagnostic immunophenotypical findings. Arch Dermatol 1989; 125: 402. 6.

Smoller BR, Stewart M, Warnke R. A case of Woringer-Kolopp disease with Ki-1 (CD30) + cytotoxic/suppressor cells. Arch Dermatol 1992; 128: 526.

7.

Wood GS, Weiss LM, Hu CH, et al. T-cell antigen deficiencies and clonal rearrangements of $\mathrm{T}$-cell receptor genes in pagetoid reticulosis (Woringer-Kolopp disease). N Engl J Med 1988; 318: 164.

8.

Haghighi B, Smoller BR, LeBoit PE, Warnke RA, Sander CA, Kohler S. Pagetoid reticulosis (Woringer-Kolopp disease): an immunophenotypic, molecular, and clinicopathologic study. Mod Pathol 2000; 13: 502.

9. 
Kaudewitz P, Stein H, Dallenbach F, et al. Primary and secondary cutaneous Ki-1+ (CD30+) anaplastic large cell lymphomas. Morphologic, immunohistologic, and clinicalcharacteristics. Am J Pathol 1989; 135: 359.

10.

Berti E, Tomasini D, Vermeer MH, Meijer CJ, Alessi E, Willemze R. Primary cutaneous CD8-positive epidermotropic cytotoxic $\mathrm{T}$ cell lymphomas. A distinct clinicopathological entity with an aggressive clinical behavior. Am J Pathol 1999; 155: 483. 


\section{Figures and tables}

Fig. 1. Clinical appearance of the lesion. (A) A hypopigmented and hyperkeratotic plaque involving the dorsum of the right foot. (B) The lesion involved also the sole.
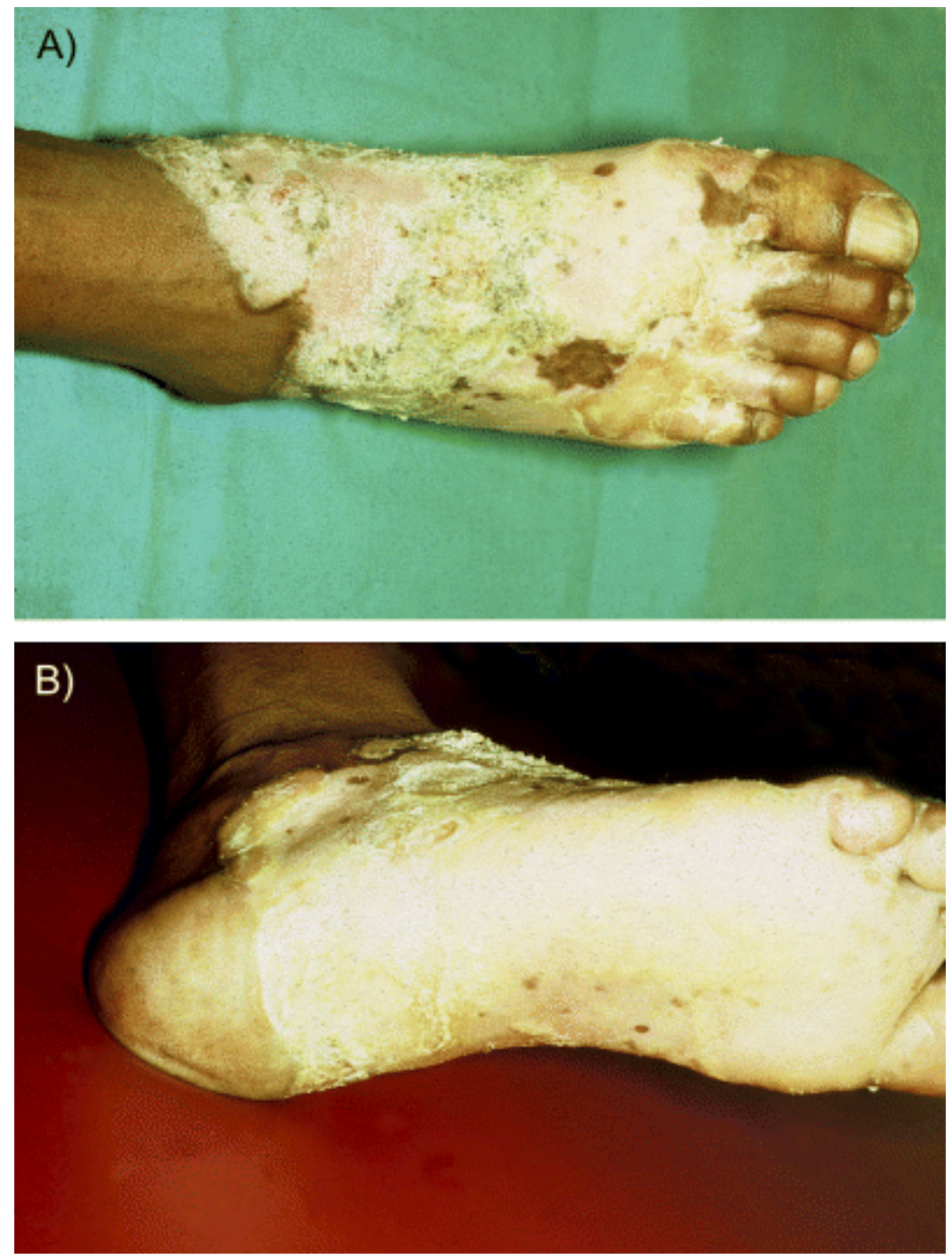
Fig. 2. Histopathological features. (A) Scanning power showing hyperplastic epidermis and an underlying band-like infiltrate along the papillary dermis. (B) Higher magnification showed prominent epidermotropism of atypical lymphocytes with hyperchromatic and pleomorphic nuclei.
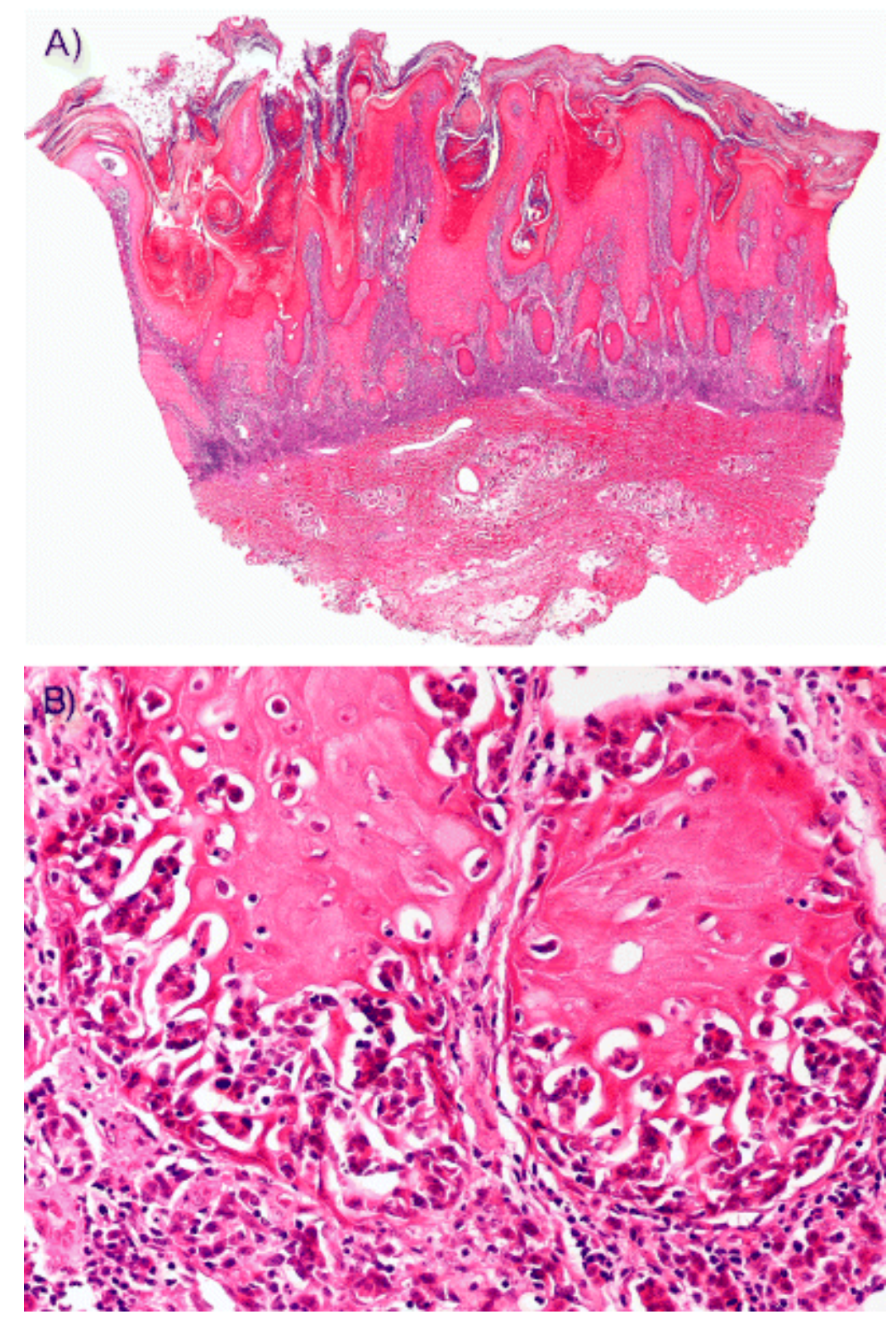
Fig. 3. Immunostaining for CD8. (A) Scanning power showing that most of the infiltrate expressed CD8 immunoreactivity. (B) Higher magnification showed that most of the epidermotropic lymphocytes expressed this cytotoxic/suppressor phenotype.

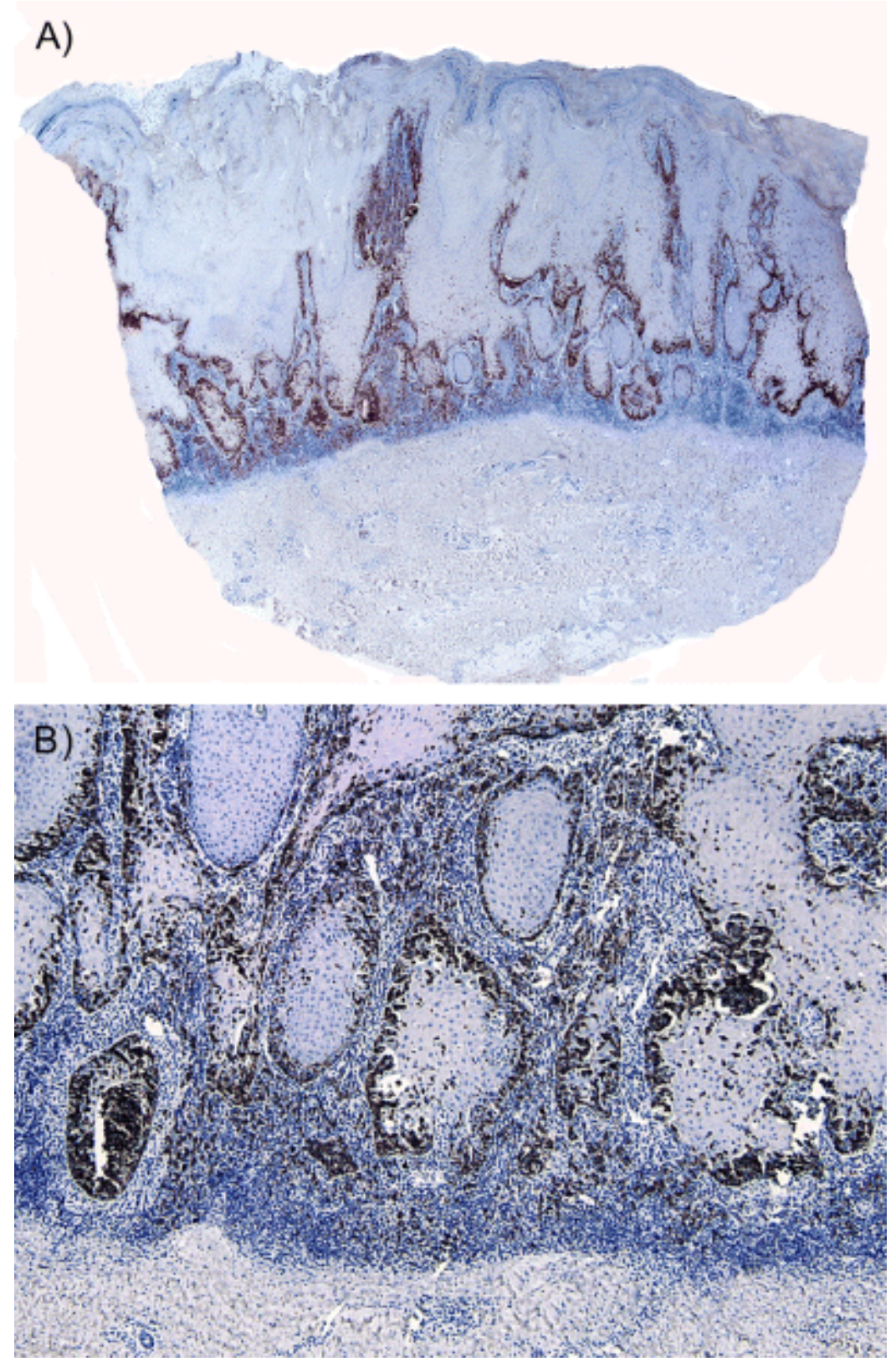


Fig. 4. Immunostaining for CD30. (A) Scanning power showing that most of the cells of the infiltrate involving the superficial dermis and the epidermis expressed immunoreactivity for CD30. (B) Higher magnification showing strong immunoexpression for CD30 in most of the intra-epidermal lymphocytes.
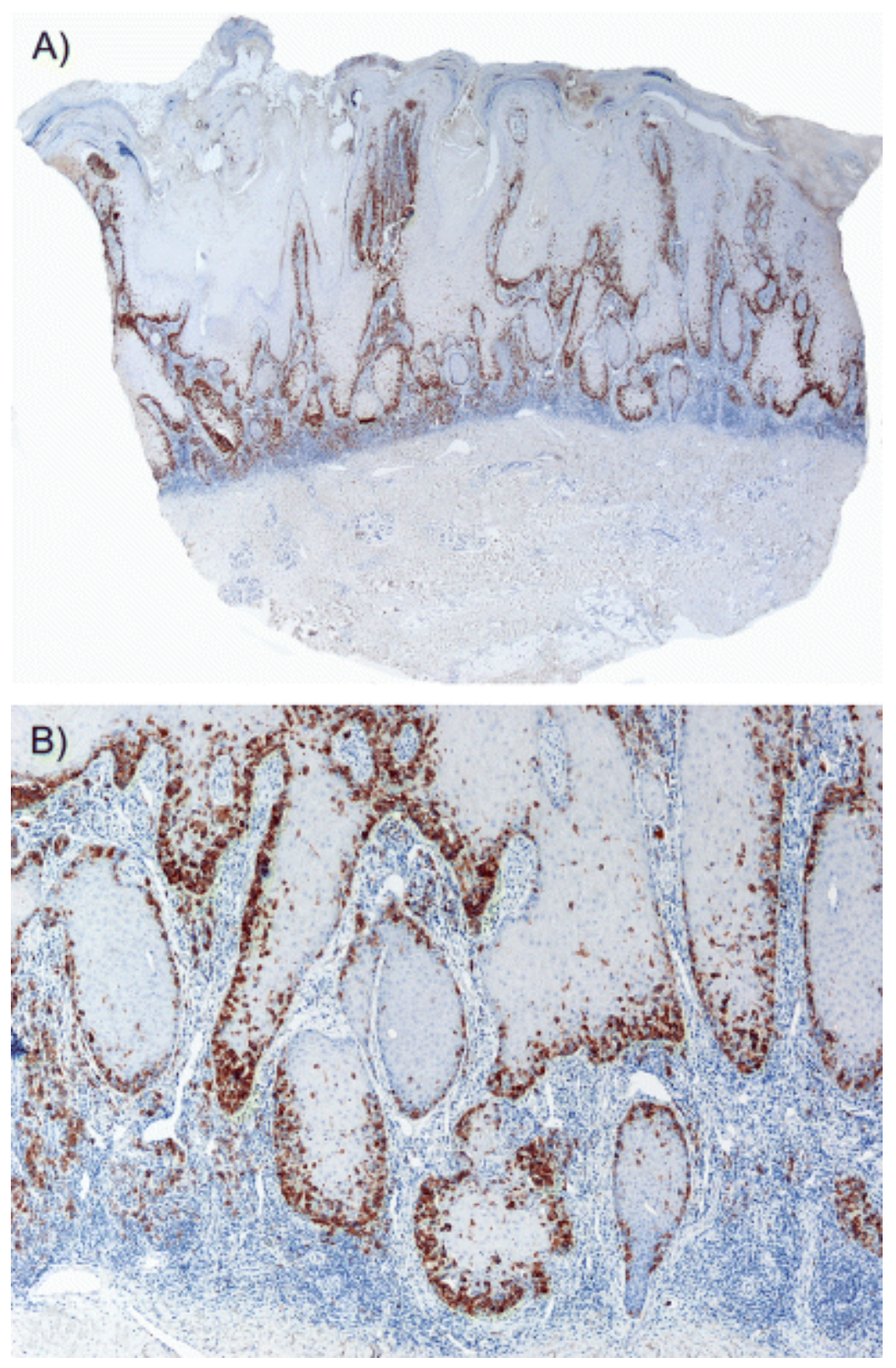
Table 1. Cases of pagetoid reticulosis of Woringer-Kolopp type with marked CD30 positivity

\begin{tabular}{|c|c|c|c|c|c|c|}
\hline Author & Case & $\begin{array}{c}\text { Age } \\
\text { (years)/sex }\end{array}$ & $\begin{array}{c}\text { Location and size of the } \\
\text { lesions }\end{array}$ & Duration & Phenotype & $\begin{array}{l}\text { Percentage of intra-epidermal } \\
\text { CD30+ cells }\end{array}$ \\
\hline \multirow[t]{2}{*}{$\begin{array}{l}\text { Mielke et } \\
\text { al. } .5\end{array}$} & 2 & $31 / \mathrm{M}$ & $\begin{array}{l}\text { Dorsum of the hand and } \\
2.5 \times 1.8 \mathrm{~cm}\end{array}$ & 6 years & $\begin{array}{l}\text { Double } \\
\text { CD4/CD8- }\end{array}$ & 60 \\
\hline & 3 & $26 / \mathrm{M}$ & Forearm and $1 \times 2 \mathrm{~cm}$ & 3 months & $\mathrm{CD} 4+, \mathrm{CD} 8-$ & 20 \\
\hline $\begin{array}{l}\text { Smoller et } \\
\text { al. } \underline{6} *\end{array}$ & & $60 / \mathrm{F}$ & $\begin{array}{l}\text { Hand and forearm, and > } \\
30 \mathrm{~cm}\end{array}$ & 40 years & CD4-, CD8+ & $>50$ \\
\hline \multirow{2}{*}{$\begin{array}{l}\text { Haghighi et } \\
\text { al. } \underline{8}\end{array}$} & 5 & $43 / \mathrm{F}$ & Tongue and $0.6 \mathrm{~cm}$ & 3 months & $\begin{array}{l}\text { Double } \\
\text { CD4/CD8- }\end{array}$ & $>50$ \\
\hline & 6 & $67 / F$ & Arm and $4 \mathrm{~cm}$ & 1 year & $\begin{array}{l}\text { CD8+, CD4 not } \\
\text { done }\end{array}$ & $>50$ \\
\hline $\begin{array}{l}\text { Current } \\
\text { report }\end{array}$ & & $41 / \mathrm{M}$ & Almost entire foot & 20 years & $\mathrm{CD} 4-, \mathrm{CD} 8+$ & $>90$ \\
\hline \multicolumn{7}{|c|}{ F, female; M, male. } \\
\hline
\end{tabular}

